\section{References}

1. Philip AG. The evolution of neonatology. Pediatr Res. 2005;58:799-815.

2. Carvalho FL, Mezzacappa MA, Calil R, Machado HC. Incidence and risk factors of accidental extubation in a neonatal intensive care unit. J Pediatr (Rio J). 2010;86:189-95.

3. Brown MS. Prevention of accidental extubation in newborns. Am J Dis Child. 1988;142:1240-3.

4. Little LA, Koenig JC Jr, Newth CJ. Factors affecting accidental extubations in neonatal and pediatric intensive care patients. Crit Care Med. 1990;18:163-5.

5. Loughead JL, Brennan RA, DeJuilio P, Camposeo V, Wengert J, Cooke D. Reducing accidental extubation in neonates. Jt Comm J Qual Patient Saf. 2008;34:164-170, 125.

6. Spence K, Barr P. Nasal versus oral intubation for mechanical ventilation of newborn infants. Cochrane Database Syst Rev. 2000: CD000948.

7. Whyte $\mathrm{KL}$, Levin R, Powls A. Clinical audit: optimal positioning of endotracheal tubes in neonates. Scott Med J. 2007;52:25-7.

8. Bhandari V, Bergqvist LL, Kronsberg SS, Barton BA, Anand $\mathrm{KJ}$; NEOPAIN Trial Investigators Group. Morphine administration and short-term pulmonary outcomes among ventilated preterm infants. Pediatrics. 2005;116:352-9.

9. Morley CJ, Davis PG, Doyle LW, Brion LP, Hascoet JM, Carlin JB, et al. Nasal CPAP or intubation at birth for very preterm infants. $N$ Engl J Med. 2008;358:700-8.

10. SUPPORT Study Group of the Eunice Kennedy Shriver NICHD Neonatal Research Network. Early CPAP versus surfactant in extremely preterm infants. N Engl J Med. 2010 May 16. [Epub ahead of print]

11. Verder $H$, Bohlin K, Kamper J, Lindwall R, Jonsson B. Nasal CPAP and surfactant for treatment of respiratory distress syndrome and prevention of bronchopulmonary dysplasia. Acta Paediatr. 2009;98:1400-8.

12. Bhandari V. Nasal intermittent positive pressure ventilation in the newborn: review of literature and evidence-based guidelines. J Perinatol. 2009 Oct 22 [Epub ahead of print].

13. Kugelman A, Feferkorn I, Riskin A, Chistyakov I, Kaufman B, Bader D. Nasal intermittent mandatory ventilation versus nasal continuous positive airway pressure for respiratory distress syndrome: a randomized, controlled, prospective study. J Pediatr. 2007; 150:521-6.

14. Sai Sunil Kishore M, Dutta S, KumarP. Early nasal intermittent positive pressure ventilation versus continuous positive airway pressure for respiratory distress syndrome. Acta Paediatr. 2009;98:1412-5.

15. Khalaf MN, Brodsky N, Hurley J, Bhandari V. A prospective randomized, controlled trial comparing synchronized nasal intermittent positive pressure ventilation versus nasal continuous positive airway pressure as modes of extubation. Pediatrics. 2001;108:13-7.
16. Santin R, Brodsky N, Bhandari V. A prospective observational pilot study of synchronized nasal intermittent positive pressure ventilation (SNIPPV) as a primary mode of ventilation in infants $>$ or $=28$ weeks with respiratory distress syndrome (RDS). J Perinatol. 2004; $24: 487-93$.

17. Kulkarni A, Ehrenkranz RA, Bhandari V. Effect of introduction of synchronized nasal intermittent positive-pressure ventilation in a neonatal intensive care unit on bronchopulmonary dysplasia and growth in preterm infants. Am J Perinatol. 2006;23:233-40.

18. Bhandari V, Gavino RG, Nedrelow JH, Pallela P, Salvador A, Ehrenkranz RA, et al. A randomized controlled trial of synchronized nasal intermittent positive pressure ventilation in RDS. J Perinatol. 2007;27:697-703.

19. Barrington KJ, Bull D, Finer NN. Randomized trial of nasal synchronized intermittent mandatory ventilation compared with continuous positive airway pressure after extubation of very low birth weight infants. Pediatrics. 2001;107:638-41.

20. Friedlich $P$, Lecart $C$, Posen R, Ramicone E, Chan L, Ramanathan $R$. A randomized trial of nasopharyngeal-synchronized intermittent mandatory ventilation versus nasopharyngeal continuous positive airway pressure in very low birth weight infants after extubation. J Perinatol. 1999;19:413-8.

21. Bhandari V. Non-invasive ventilation of the sick neonate: evidencebased recommendations. J Neonatol. 2006;20:214-21.

22. Ramanathan R, Sekar KC, Rasmussen M, Bhatia J, Soll RF. Nasal intermittent positive pressure ventilation (NIPPV) versus synchronized intermittent mandatory ventilation (SIMV) after surfactant treatment for respiratory distress syndrome (RDS) in preterm infants <30 weeks gestation: multicenter, randomized, clinical trial. EPAS. 2009:3212:3216. (abstract)

23. De Paoli AG, Davis PG, Lemyre B. Nasal continuous positive airway pressure versus nasal intermittent positive pressure ventilation for preterm neonates: a systematic review and meta-analysis. Acta Paediatr. 2003;92:70-5.

24. Bhandari V, Finer NN, Ehrenkranz RA, Saha S, Das A, Walsh MC, et al. Synchronized nasal intermittent positive-pressure ventilation and neonatal outcomes. Pediatrics. 2009;124:517-26.

25. Axelin A, Ojajarvi U, Viitanen J, Lehtonen L. Promoting shorter duration of ventilator treatment decreases the number of painful procedures in preterm infants. Acta Paediatr. 2009;98:1751-5.

\section{Correspondence:}

Vineet Bhandari

Yale University School of Medicine

Division of Perinatal Medicine

Department of Pediatrics; LLCI 401B

P.O. Box 208064

New Haven, CT 06520-8064 - USA

Tel.: +1 (203) 785.2613

Fax: +1 (203) 785.6974

E-mail: vineet.bhandari@yale.edu

\title{
Commentary: concerns for complementary feeding of infants in Brazil
}

\author{
Frank R. Greer*
}

The article in this issue of Jornal de Pediatria by Caetano et al. reports some disturbing practices of complementary feeding from a recent survey of 179 infants in three different municipalities in Brazil. ${ }^{1}$ As in the USA, ${ }^{2}$ the vast majority of infants are introduced to complementary feeding (including breast milk substitutes) by 4 months of age. However, in Brazil many infants are introduced to whole cow milk before 6 months of age and $80 \%$ are receiving whole milk by the end

\footnotetext{
* MD. Professor, Pediatrics, School of Medicine and Public Health, University of Wisconsin, Madison, WI, USA. Former Chairperson, American Academy of
} Pediatrics, Committee on Nutrition.

No conflicts of interest declared concerning the publication of this editorial.

Suggested citation: Greer FR. Commentary: concerns for complementary feeding of infants in Brazil. J Pediatr (Rio J). 2010;86(3):169-170. 
of the first year of life. This is unlike the USA where whole milk does not replace infant formula until 12 months of age in accordance with the recommendations of the American Academy of Pediatrics. ${ }^{2,3}$ Even more unsettling in this dietary survey of infant feeding practices in Brazil, is the fact that both whole cow's milk and infant formula are often modified by the addition of sugar and/or chocolate even in infants less than 6 months of age. Admittedly, over $50 \%$ of infants born in the USA currently receive infant formula at no cost through a US government supplemental food program for mothers, infants, and children.4,5 The relatively high cost of infant formula for Brazilian infants may explain its use in only $12 \%$ of infants under the age of 6 months and in only $6.7 \%$ of infants greater than 6 months of age. It may also explain the high percentage of inappropriately diluted or inappropriately concentrated (with other additives including sugar and chocolate) feedings of infant formula.

The paper by Caetano et al. would support the World Health Organization (WHO) recommendations for exclusive breastfeeding through 6 months of age given the inadequacies of the breast milk substitutes currently utilized in Brazil. Oddly enough, the present feeding pattern of infants in Brazil in the first year of life resembles that seen in the USA prior to 1972, when similar inappropriate feeding practices with breast milk substitutes, including whole milk with attendant nutrient deficiencies, were observed. ${ }^{5}$ This resulted in the creation of the US government's Special Supplemental Nutrition Program for Women, Infants, and Children (often called the WIC program) in 1972-1974. ${ }^{5}$ Though the nutritional deficiencies were largely eliminated, this program had a very negative impact on breastfeeding in this population which has only recently been addressed. 5

The authors of the Brazilian study also point out the specific nutrient deficiencies associated with complementary feeding in the infants surveyed during the first year of life. Most notably these are zinc, iron, and vitamin A (vitamin $D$ intake was not assessed). Iron deficiency is the most worrisome given its potential for long-term negative impact on neuro-developmental outcome. As pointed out by the authors, the deficiency of iron maybe largely due to the use of whole milk as a complementary food. On the contrary, the intake of "meat" (see Table 3) was relatively high in these children, though we are not told whether or not this was red meat, which would be a good source of iron and zinc. It is also not clear in this paper whether or not the cereals fed to infants were iron fortified as in the USA. Intake of processed foods such as cookies and fruit drinks is also very high in Brazil, which would be poor sources of these nutrients. The high content of fat and sugar in these foods is also of concern. In a recent report from the USA, findings for intakes of processed foods were similar during the second 6 months of life, and infants were noted to frequently have eaten fast foods or carryout foods by 10 months of age. 6

Finally the authors express concern that these unhealthy feeding practices in Brazilian infants in the first year of life may "potentiate the risk of developing diseases such as cardiovascular disorders." 1 This of course cannot be demonstrated in this cross-sectional observational study in which no anthropometric data is provided for these infants. There has been much hype in the pediatric literature regarding dietary intake in infants and future "metabolic programming." It has long been known that infants can regulate their dietary intake as complementary foods begin to replace breast milk or formula. A number of studies have shown previously that complementary foods introduced in the first year of life have limited impact on overall infant growth during this period of time. ${ }^{7-9}$ The impact of the type and amounts of complementary foods introduced in the first year of life on obesity and cardiovascular diseases later in life will need further prospective, longitudinal studies. In the mean time, renewed emphasis on the exclusive breastfeeding of infants in Brazil for the first 6 months of life seems very appropriate, given the introduction of inappropriate complementary foods.

\section{References}

1. Caetano MC, Ortiz TT, da Silva SG, de Souza FI, Sarni RO. Complementary feeding: inappropriate practices in infants. J Pediatr (Rio J). 2010;86:196-201.

2. Grummer-Strawn LM, Scanlon KS, Fein SB. Infant feeding and feeding transitions during the first year of life. Pediatrics. 2008;122 Suppl 2:S36-42.

3. Formula feeding of term infant. In: Pediatric Nutrition Handbook. 6th Edition. American Academy of Pediatrics, Elk Grove Village, II. pp 76-77.

4. WIC Food Packages. [website] Food and Nutrition Service. www. fns.usda.gov/wic/benefitsandservices/foodpkg.htm. Access: $31 / 03 / 2010$

5. www.fns.usda.gov/wic/benefitsandservices/foodpkg.htm. WIC Food Packages: Time for a Change. Institute of Medicine, The National Academies Press, Washington, DC. 2006.

6. Fein SB, Labiner-Wolfe J, Scanlon KS, Grummer-Strawn LM. Selected complementary feeding practices and their association with maternal education. Pediatrics. 2008;122 Suppl 2:S91-7.

7. Mehta KC, Specker BL, Bartholmey S, Giddens J, Ho ML. Trial on timing of introduction to solid foods and food type on infant growth. Pediatrics. 1998:102:569-73.

8. Dewey KG, Cohen RJ, Brown KH, Rivera LL. Age of introduction of complementary foods and growth of term, low-birthweight, breastfed infants: a randomized intervention study in Honduras. Am J Clin Nutr. 1999;69:679-86.

9. Morgan JB, Lucas A, Fewtrell MS. Does weaning influence growth and health up to 18 months? Arch Dis Child. 2004;89:728-33.

Correspondence:

Frank R. Greer

Meriter Hospital Perinatal Center

202 S Park St, Madison, WI 53715 - USA

E-mail: frgreer@pediatrics.wisc.edu 